UDC 316.3:17.022.1

LBC 60.523

\title{
MORAL AND SPIRITUAL VALUES AS THE BASIS OF NATIONAL SECURITY IN THE DIGITAL AGE
}

\author{
Ruslan V. Gavva \\ Moscow (Senkevich) State Institute of Physical Culture, Sports and Tourism, \\ Moscow, Russian Federation \\ Eduard M. Molchan \\ Moscow (Senkevich) State Institute of Physical Culture, Sports and Tourism, \\ Moscow, Russian Federation
}

\begin{abstract}
The article studies moral and spiritual values as regulators of relations in social systems that determine the worldview of the individual and the development vector of modern society, building value orientations as the basis of national security. Attention is drawn to the fact that the mass culture of the virtual Internet space freely erases the national borders of countries and continents, creating conflicts and crises on a global scale. The article substantiates the need for a modern state to support its own culture and values in the context of information globalization, to prevent the imposition of the values of other cultures, and to develop conditions for optimal integration without destructive consequences for society. It is shown that to ensure the national security of modern Russian society, it is necessary to: form public and national consciousness; maintain the cultural and value potential of the nation; develop spiritual and moral values of dialogical interaction of communities; develop a stable spiritual immunity of the individual based on the national values of the state; include a cultural and value dominant in development strategy of the country.

Key words: moral and spiritual values, information globalization, personality, social systems, modern Russian society, value potential, educational policy, public national consciousness.
\end{abstract}

УДК 316.3:17.022.1

ББК 60.523

\section{ДУХОВНО-НРАВСТВЕННЫЕ ЦЕННОСТИ КАК ОСНОВА НАЦИОНАЛЬНОЙ БЕЗОПАСНОСТИ В ЦИФРОВУЮ ЭПОХУ}

\author{
Руслан Витальевич Гавва \\ Московский государственный институт физической культуры, спорта и туризма им. Ю.А. Сенкевича, \\ г. Москва, Российская Федерация \\ Эдуард Михайлович Молчан \\ Московский государственный институт физической культуры, спорта и туризма им. Ю.А. Сенкевича, \\ г. Москва, Российская Федерация
}

¿ิ

Аннотация. В статье исследуются духовно-нравственные ценности как регуляторы отношений в соци-
альных системах, определяющие мировоззрение личности и вектор развития современного общества, выст-
раивающие ценностные ориентации как основу национальной безопасности. Акцентируется внимание на
том, что массовая культура интернет-пространства беспрепятственно стирает национальные границы стран
и континентов, создавая конфликты и кризисы мирового масштаба. Обоснована необходимость обеспече-
ния современным государством поддержки собственной культуры и ценностей в условиях информацион-
ной глобализации, недопущения навязывания ценностей иных культур, выработки условий оптимальной
интеграции без деструктивных последствий для общества. Показано, что для обеспечения национальной 


\section{НАУЧНЫЕ СООБЩЕНИЯ}

безопасности современного российского общества необходимо: формировать общественное, национальное сознание; поддерживать культурно-ценностный потенциал нации; вырабатывать духовно-нравственные ценности диалогического взаимодействия сообществ; развивать устойчивый духовный иммунитет личности, основанный на национальных ценностях государства; включить в стратегию развития страны культурноценностную доминанту.

Ключевые слова: духовно-нравственные ценности, информационная глобализация, личность, социальные системы, современное российское общество, ценностный потенциал, образовательная политика, общественное национальное сознание.

Проблема определения стратегий развития современного общества в ходе современных цивилизационных процессов представляется многофакторной и многофункциональной, затрагивает генно-историческое развитие человечества, включает в себя на генетическом и духовном уровнях энергийно-информационную составляющую поколений людей и структурно детерминирована окружающими реальностями: природной, социальной и виртуальной. Раскрывая особенности функционирования социальных систем на макроуровне и взаимосвязь элементов этих систем на микроуровнях, необходимо определить, что лежит в основании фундамента национальной безопасности современного российского общества. Смысл такого философского исследования состоит в том, чтобы не только прояснить те мировоззренческие структуры, которые определяют образ мира и образ жизни людей, но и, рефлектируя над этими структурами, предложить возможные варианты новых жизненных смыслов и ценностей.

В основе развития каждой страны лежат духовно-нравственные ценности, которые имеют разную иерархическую структуру в зависимости от государства. XXI в. особо остро выделяет проблематичность кризиса ценностей мировых сообществ, подобные состояния сопровождаются обновлением парадигм развития систем образования, активизацией процессов становления мирового правительства и тотального подчинения цифровым технологиям всего человечества [Астафьева 2014, 75]. Кто мы, люди виртуального мира, сверхличности или рабы виртуальности? Какие ценности для нас будут актуальны и к чему мы приведем цивилизацию в будущем?

Современное общество столкнулось с невиданным усложнением организации функционирования социальных систем. Сложность приобретает окраску искусственной навязчи- вости, нагнетания ситуации хаоса и промывания «мозгов» через электронные СМИ. В последних огромная часть информации недостоверна, практика расходится с делом, экспансия ценностей западного мира актуализирует внимание к осознанности своего состояния и общества. Национальная безопасность современного российского общества взаимосвязана с духовной, экономической, военной, информационной, экологической, техногенной и другими видами безопасности. В условиях нестабильности развития современного общества, когда из хаоса выстраивается порядок, необходимо формирование такого ценностносмыслового основания, которое способствовало бы сохранению идентичности и национальных особенностей во время адаптации к разного рода новациям и преобразованиям. Таким системообразующим элементом национальной безопасности современного российского общества являются духовно-нравственные ценности, образующие ядро ценностного основания социальных систем и определяющие характер взаимоотношений личности [Belsky et al. 2019].

Жизнь человека состоит не только из удовлетворения материальных потребностей, но и из стремления к преобразованию внутреннего мира, духовных исканий. Духовнонравственные ценности как регуляторы отношений в социальных системах определяют мировоззрение личности, выстраивают ценностные ориентации, его культуру [Yanich et al. 2019]. Взаимосвязь национальной безопасности и ценностных ориентаций личности определяет духовную безопасность общества как один из наиболее важных компонентов развития социальных систем. Духовная безопасность социальных систем связана с состоянием сформированности духовно-нравственных ценностей личности, уровнем развития культуры и нравственности. 
Образовательная политика современной России сталкивается с кризисом традиционных связей, утратой традиционных ценностей, когда человек полученное образование вынужден адаптировать к социальной реальности современного общества, находить или самостоятельно формировать модели поведения и взаимодействия в социальных системах. Развитие последних предполагает становление новой среды существования, новых жизненных ценностей, нового образа жизни, где в измененную социальную реальность встраивается измерение виртуальности [Майкова, Наместникова, Горбунов 2019, 149].

Становится очевидным, что прошлое, поглощенное новыми изменениями современности, отождествляется с концом исторического периода, после которого меняются основания функционирования социальных систем, трансформируется национальная культура, изменяются модели поведения в обществе с течением времени [Бельский, Майкова, Молчан 2019, 62]. Общество современной эпохи, наполненное бездуховностью, где современность изменяется с ускоряющейся быстротой, обретает мнимую определенность ценностей и идеализированных моделей будущего. Трансформация социальных систем изменяет понимание личности как существа творческого и свободного, ограничивает ее духовную свободу, навязывает модели поведения в социальных системах. Подчиненная глобализационным процессам личность утрачивает свою индивидуальную особенность, приобретает статус цифровой, виртуальной единицы. Глобализация через виртуализацию, подобно «черной дыре», как пространственно-временная воронка втягивает финансово-экономические, общественно-политические и культурные связи в виртуальный мир, функционирующий на основе цифровых технологий [Молчан 2019, 57].

Виртуальная глобализация как основной инструмент насаждения и распространения массовой культуры, переориентации человеческой массы на материальные ценности потребления ставит под угрозу национальную безопасность любого государства. Утрата духовно-нравственных ценностей государством, насаждение иной культуры и манипулирование сознанием личности в социальной или в виртуальной реальности грозит разрушением государственной идентичности, утратой патриотизма и любви к Родине. В связи с этим трансформационные процессы в области индустриальной культуры должны быть связаны с регулированием со стороны государственных структур и развитием культурной идентичности [Петрий 2017, 59].

Развитие интернет-технологий и информатизация современного общества влияют на формирование мировоззрения современного человека и систему его ценностей. Происходит непрерывная адаптация к изменяющимся условиям виртуализации современного общества. По мнению Р.В. Кончаковского, интернет-пространство - это не только структурирующая, объединяющая людей социальная технология, но и самостоятельная сфера жизни, функционирование которой приводит к трансформации существующих образовательных систем и возникновению новых. Оно предоставляет широкие возможности не только для самообразования, ведения бизнеса, общения, но и для распространения негативной и опасной информации [Кончаковский 2010].

Исследуя влияние СМИ на формирование жизненных ценностей человека, М. Маклюэн подчеркивает, что материальное ценности в интернет-пространстве преобладают над духовно-нравственными [Маклюэн 2007, 76]. Виртуальная среда является сосредоточением информационных ресурсов и продуктов, а человек стремится получать информацию. Перераспределение информационных ресурсов и продуктов создает возможность человеку обогатиться и прославиться, невзирая на общечеловеческие ценности и принципы морали.

Электронные СМИ, используя интернетпространство, оказывают существенное влияние на сознание личности, коллектива, общества. Манипуляция общественным сознанием происходит под влиянием современной медиакультуры. Погружаясь в интернет-пространство человек испытывает на себе воздействие огромного количества информационно-технологических потоков, которые влияют на сознание. СМИ, воздействуя на общество и личность, привносят иные ценности, формируют мировоззрение личности и ценностные ориен- 


\section{НАУЧНЫЕ СООБЩЕНИЯ}

тации общества, транслируют культурные достижения. Однако этот процесс остается бесконтрольным и малоизученным. П. Меркер, А. Моль, Э. Тоффлер рассматривают СМИ и интернет-ресурсы как основные факторы воздействия на мировоззрение и идеологию современного общества. Информационные ресурсы наряду с природными и финансовыми представляют ценность для общества и личности. Дж. Мур, исследовавший влияние компьютерных систем на ценности современного общества, выделил высокий статус информации как ценности информационного общества. Современное интернет-пространство изменяет ценностный потенциал общества, порождает новые возможности и потребности самореализации человека. Глобализация информационного общества позволяет мгновенно получать доступ к открытым информационным ресурсам в любой точке мира. Однако происходящие трансформации, связанные с использованием интернет-пространства, имеют сложный характер взаимоотношений и способствуют как прогрессу, так и деградации. Последняя связана с погружением в виртуальное пространство, подменой жизненных ценностей мнимыми, манипулированием сознанием, интернет-зависимостью. Человек через электронные СМИ оказывается под воздействием транслируемых ценностей и идей, заинтересованных сообществ [Маклюэн 2007, 123]. Электронные СМИ в интернетпространстве используют три типа манипуляций: подмена истинных фактов и событий так называемыми фейк-новостями; кодирование и шифрование; использование методов психологического воздействия на личность [Минеев 2012].

Распространение электронных СМИ в сети Интернет - основной фактор изменения социального бытия современного общества. Одним из вопросов является влияние интернет-пространства и СМИ на формирование духовно-нравственных ценностей личности в образовательной системе Российской Федерации. Интернет-пространство способствует прозрачности и демократизации в диалогических взаимодействиях образовательной системы. При этом государство в отношении подрастающего поколения, его социализации, воспитания, социального и культурного развития должно осуществлять управленческую деятельность, потеря взаимосвязи между образовательными системами и государством чревата негативными социальными последствиями, дезорганизацией и дисфункциональностью многих социальных институтов и подсистем. Деформация образовательной системы в современной России не в последнюю очередь связана с виртуализацией образовательного процесса и влиянием на формирование духовно-нравственных ценностей личности интернет-пространства. Сам процесс виртуализации образовательных систем заключается в воздействии интернет-пространства на реальную жизнь: виртуальные интернетмодели воздействуют на реальность социального бытия, происходят искажение реальности и подмена ценностей реальности мнимыми ценностями виртуальности. По мнению К. Шеннона [Шеннон 1963], возникновение «искаженной реальности» имеет сходство с эффектом коммуникативного шума.

Преимуществом виртуального общения является создание условий образования бизнес-структур в Интернете, которые отбирают и вовлекают в свою группу людей творческих, ярких, коммуникабельных, предприимчивых, быстро приспосабливающихся к переменам, позволяя самым находчивым личностям беспрепятственно получить статус, власть, деньги.

Воздействие интернет-пространства на социальные системы и на мировоззрение личности в ходе виртуального диалогического взаимодействия двойственно. Оно приобретает черты ценности нового типа, помогая человеку проявить свою сущность в новых условиях, приобщает личность к многовековому опыту, знаниям, ценностям через образовательные системы. Положительное влияние интернет-пространства связано с получением ценной информации, приобретением товаров и услуг, общением, работой и т. д. Отрицательное влияние проявляется в воздействии негативной информации на личность, манипуляции сознанием, зависимости от онлайн-игр, росте числа психических расстройств.

Виртуальная глобализация производит столкновение ценностей культур различных сообществ, синтезируя общую мировую систему культурных ценностей. Происходит по- 
Р.В. Гавва, Э.М. Молчан. Духовно-нравственные ценности как основа национальной безопасности

глощение культур отдельных государств и исчезновение национальной идентичности, растворение ценностей в новой мировой системе. Формируется новый тип человека «гражданин мира», который не имеет принадлежности к какому-либо обществу. Естественно, такой человек не будет патриотом своей страны. При этом полная изоляция страны от внешнего мира может спровоцировать культурную изоляцию и зародить ростки национализма. Здесь необходима «золотая середина», где внешнее и внутреннее оптимально соотнесены. Соединив в себе культуры разных народов и позаимствовав не самые лучшие образцы, мировая культура разорвала национальное пространство ценностей и вошла в нашу жизнь, изменив отношение к себе и стране.

На наш взгляд, устойчивое общественное развитие возможно только на ценностях национальной культуры, когда в основу развития общества будут положены традиционные ценности народа. Задача современного государства в условиях информационной глобализации - обеспечить поддержку собственной культуры и собственных ценностей и при взаимодействии с другими культурами выработать условия оптимальной интеграции, не допустить навязывания чуждых ценностей.

Таким образом, для обеспечения национальной безопасности современного российского общества в цифровую эпоху необходимо: формировать общественное национальное сознание; поддерживать культурно-ценностный потенциал нации; выработать духовно-нравственные ценности диалогического взаимодействия сообществ; формировать устойчивый духовный иммунитет личности, основанный на национальных ценностях государства; включить в стратегию развития страны культурноценностную доминанту становления современного российского общества. Стратегическим направлением развития образовательной политики Российской Федерации в интересах устойчивого и безопасного развития социальных систем выступает процесс формирования ценностного потенциала личности и общества. Это проблема актуализируется в силу трансформации и модернизации российского общества, воздействия виртуальной информационной глобализации, вхождения в информационно-культурное мировое пространство.

\section{СПИСОК ЛИТЕРАТУРЫ}

Астафьева 2014 - Астафьева О.Н. Теория и практика культурной политики: смыслы «образы» действия // Гос. служба. 2014. № 1. С. 72-78.

Бельский, Майкова, Молчан 2019-Бельский В.Ю., Майкова В.П., Молчан Э.М. Традиции и новации в формировании духовно-нравственных ценностей личности в образовании // Coциально-гуманитарные знания. 2019. № 5. С. $60-67$.

Кончаковский 2010 - Кончаковский Р.В. Сетевое интернет-сообщество как социокультурный феномен: автореф. дис. ... канд. социол. наук. Екатеринбург, 2010.

Майкова, Наместникова, Горбунов 2019 - Майкова В.П., Наместникова И.В., Горбунов В.С. Системный подход как основа научной методологии // Вестник Московского государственного областного университета. Серия: Философские науки. 2019. № 1. С. 148-158.

Маклюэн 2007 - Маклюэн М. Понимание Медиа: внешние расширения человека. М.: Кучково поле, 2007.

Минеев 2012 - Минеев В.В. Введение в историю и философию науки: учебник для вузов. Изд. 3-е, перераб. и доп. Красноярск: КГПУ, 2012.

Молчан 2019 - Молчан Э.М. Влияние цифровизации на формирование духовно-нравственных ценностей субъектов взаимодействия в эпоху глобализации // Вестник Московского государственного областного университета. Серия: Философские науки. 2019. № 2. С. 55-66.

Петрий 2017 - Петрий П.В. Общественный идеал как фактор модернизации России в условиях глобализации // Вестник Московского государственного областного университета. Серия: Философские науки. 2017. № 2. С. 55-63.

Шеннон 1963 - Шеннон К. Работы по теории информации и кибернетике. М.: Изд-во иностр. лит., 1963.

Belsky et al. 2019 - Belsky V.Yu., Maykova V.P., Kostadinovich D., Molchan E.M. Value Basis as a Factor of Social Systems Stability // The International Science and Culture Center for Academic Contacts (ISCCAC) is Pleased to Announce the $2^{\text {nd }}$ International Conference on Contemporary Education, Social Sciences and Ecological Studies (CESSES 2019). The Conference Will Be Held on June 05-06, 2019 in Moscow. Moscow: [s. 1.], 2019. P. 1189-1192. DOI: https://doi.org/10.2991/cesses-19.2019.265.

Yanich et al. 2019 - Yanich M., Pesotsky V.A., Maykova V.P., Molchan E.M. Spiritual and Moral Values as a System-forming Factor of Social Systems // The International Science and Culture Center for 
Academic Contacts (ISCCAC) is Pleased to Announce the $2^{\text {nd }}$ International Conference on Contemporary Education, Social Sciences and Ecological Studies (CESSES 2019). The Conference Will Be Held on June 05-06, 2019 in Moscow. Moscow: [s. 1.], 2019. P. 1185-1188. DOI: https://doi.org/10.2991/cesses-19.2019.264.

\section{REFERENCES}

Astaf'eva O.N., 2014. Theory and Practice of Cultural Policy: Meanings of "Images" Actions. Gos. sluzhba, no. 1, pp. 72-78.

Bel'skij V.Yu., Majkova V.P., Molchan E.M., 2019. Traditions and Innovations in the Formation of Spiritual and Moral Values of the Individual in Education. Sotsialno-gumanitarnye znaniya, no. 5, pp. 60-67.

Konchakovskij R.V., 2010. Online Community as a Socio-Cultural Phenomenon. Cand. sociol. sci. abs. diss. Ekaterinburg.

Majkova V.P., Namestnikova I.V., Gorbunov V.S., 2019. System Approach as the Basis of Scientific Methodology. Vestnik Moskovskogo gosudarstvennogo oblastnogo universiteta. Seriya: Filosofskie nauki, no. 1, pp. 148-158.

Maklyuen M., 2007. Understanding Media: External Human Extensions. Moscow, Kuchkovo pole Publ., 2007.

Mineev V.V., 2012. Introduction to the History and Philosophy of Science: Textbook for Universities. Krasnoyarsk, KGPU, 2012.

Molchan E.M., 2019. Influence of Digitalization on the Formation of Spiritual and Moral Values of
Interaction Subjects in the Era of Globalization. Vestnik Moskovskogo gosudarstvennogo oblastnogo universiteta. Seriya: Filosofskie nauki, no. 2, pp. 55-66.

Petrij P.V., 2017. Social Ideal as a Factor of Russia's Modernization in the Context of Globalization. Vestnik Moskovskogo gosudarstvennogo oblastnogo universiteta. Seriya: Filosofskie nauki, no. 2, pp. 55-63.

Shennon K., 1963. Works on Information Theory and Cybernetics. Moscow, Izd-vo inostrannoy literatury.

Belsky V.Yu., Maykova V.P., Kostadinovich D., Molchan E.M., 2019. Value Basis as a Factor of Social Systems Stability. The International Science and Culture Center for Academic Contacts (ISCCAC) is Pleased to Announce the $2^{\text {nd }}$ International Conference on Contemporary Education, Social Sciences and Ecological Studies (CESSES 2019). The Conference Will Be Held on June 5-6, 2019 in Moscow. Moscow, pp. 1189-1192. DOI: https://doi.org/10.2991/ cesses-19.2019.265.

Yanich M., Pesotsky V.A., Maykova V.P., Molchan E.M., 2019. Spiritual and Moral Values as a System-Forming Factor of Social Systems. The International Science and Culture Center for Academic Contacts (ISCCAC) is Pleased to Announce the $2^{\text {nd }}$ International Conference on Contemporary Education, Social Sciences and Ecological Studies (CESSES 2019). The Conference Will Be Held on June 5-6, 2019 in Moscow. Moscow, pp. 1185-1188. DOI: https:// doi.org/10.2991/cesses-19.2019.264.

\section{Information About the Authors}

Ruslan V. Gavva, Candidate of Sciences (Economics), Associate Professor, Vice-Rector, Moscow (Senkevich) State Institute of Physical Culture, Sports and Tourism, Kronshtadtsky Blvd, 43A, 125499 Moscow, Russian Federation, gavva@rambler.ru, https://orcid.org/0000-0002-4781-8550

Eduard M. Molchan, Candidate of Sciences (Pedagogy), Research Associate, Moscow (Senkevich) State Institute of Physical Culture, Sports and Tourism, Kronshtadtsky Blvd, 43A, 125499 Moscow, Russian Federation, ed.molchan2015@yandex.ru, https://orcid.org/0000-0002-6257-8030

\section{Информация об авторах}

Руслан Витальевич Гавва, кандидат экономических наук, доцент, проректор Московского государственного института физической культуры, спорта и туризма им. Ю.А. Сенкевича, Кронштадтский бул., 43А, 125499 г. Москва, Российская Федерация, gavva@rambler.ru, https://orcid.org/0000-0002-4781-8550

Эдуард Михайлович Молчан, кандидат педагогических наук, научный сотрудник Московского государственного института физической культуры, спорта и туризма им. Ю.А. Сенкевича, Кронштадтский бул., 43А, 125499 г. Москва, Российская Федерация, ed.molchan2015@yandex.ru, https://orcid.org/0000-0002-6257-8030 